\title{
DETEKSI JARAK KEDATANGAN KERETA API PADA PERSIMPANGAN JALAN MENGGUNAKAN SENSOR ACCELEROMETER DAN NEURAL NETWORK
}

\author{
Heri Ardiansyah \\ Program Studi Teknik Komputer - Fakultas Sains Teknologi dan Pendidikan \\ Universitas Muhammadiyah Lamongan \\ e-mail: heri@umla.ac.id \\ Jl. Raya Plalangan Plosowahyu KM.3 Lamongan 62251 Jawa Timur
}

\begin{abstract}
ABSTRAK
Suatu sistem pengawasan lalu lintas kereta api di persimpangan sudah menjadi hal mutlak yang harus disediakan baik secara manual maupun otomatis, menggunakan sumber daya manusia atau hanya memanfaatkan peralatan elektrik dan elektronik. Telah banyak penelitian yang memanfaatkan perangkat elektronik dalam berbagai model dan aktualisasi sebenarnya, diantaranya penggunaan sensor ultrasonik, sensor infra merah, mikropon, sensor GPS, kamera, dan sensor magnetik. Adapun dalam penelitian ini menggunakan sensor accelerometer untuk mendeteksi getaran yang dihasilkan oleh kereta api yang dalam hal ini adalah getaran rel. Pola frekuensi getaran rel tersebut akan dibedakan antara kereta api dengan pola getaran yang disebabkan oleh kendaraan lain yang melintasi jalan persimpangan rel yakni truk, mobil, dan sepeda motor. Dengan algoritma jaringan syaraf tiruan (neural network), hasil penelitian menunjukkan bahwa pola getaran rel yang dihasilkan oleh kereta api dapat dibedakan dari kendaraan lain. Sedangkan jarak terjauh yang dapat dideteksi oleh sensor accelerometer MEMS (micro-electro-mechanical-system) ini adalah sebesar 74 meter. Di samping itu, keunggulan dari penggunaan sensor accelerometer adalah untuk efisiensi perangkat, dimana sensor hanya ditempatkan pada situs pemantauan dan tidak dipasang di jarak tertentu yang cukup jauh seperti pada penggunaan sensor-sensor lain.
\end{abstract}

Kata kunci: kereta api, getaran, accelerometer, neural network, persimpangan

\section{PENDAHULUAN}

Pada suatu persimpangan jalan kereta api dengan penjagaan petugas dan fasilitas persinyalan masih juga terdapat kemungkinan terjadi kecelakaan kereta seperti yang tercatat di wilayah Jakarta [1] sebanyak 198 kasus hingga awal Oktober. Namun pada dasarnya kejadian kecelakaan di persimpangan kereta api merupakan kelalaian pengendara yang melintasi rel baik disengaja maupun tidak disengaja dan bukan kesalahan pihak penjaga perlintasan. Dari kondisi tersebut, kita dapat meminimalisir atau menghilangkan kemungkinan kecelakaan dengan menambahkan perangkat peringatan dini akan kedatangan kereta api pada persimpangan jalan rel terlebih pada persimpangan yang tidak ada penjaganya.

Suatu kereta api yang sedang berjalan menjadi pembangkit gelombang getaran pada rel yang dilewatinya. Sepanjang jalur rel jika diamati bunyinya maka pada jarak beberapa ratus meter pun akan terdengar suara getaran yang menandakan rel telah bergetar meskipun dengan tingkat kekuatan getaran yang rendah. Getaran yang terjadi pada rel akan dibaca oleh sensor accelerometer untuk memperkirakan sampai sejauh mana jarak yang dapat dibaca sensor ini. Jarak deteksi ini akan berguna untuk dijadikan sinyal peringatan kedatangan bahwa kereta api sudah mendekat. Untuk mengenali pola frekuensi kereta api maupun kendaraan lain yang melintas di persimpangan rel, getaran yang dibaca oleh sensor accelerometer dikenali pola frekuensinya menggunakan algoritma neural network.

Pada penelitian sebelumnya, deteksi getaran memanfaatkan sensor accelerometer juga digunakan pada sistem peringatan 
kedatangan kereta api [2] yakni tipe accelerometer piezoelektrik. Pembuatan sistem dengan sensor accelerometer ini salah satunya bertujuan untuk mensupport penggunaan sensor berat yang cukup konvensional seperti sensor magnetic [3] yang membutuhkan konsumsi listrik lebih tinggi.

Dengan menggunakan sensor mems accelerometer, diharapkan dapat dirancang suatu sistem peringatan dini yang dapat mendeteksi kedatangan kereta api dari jarak tertentu yang mudah dibangun dan cukup memadai.

\section{DASAR TEORI}

Untuk mendapatkan getaran sinyal frekuensi, maka getaran sinyal waktu ditransformasikan [4] melalui algoritma Fast Fourier Transform (FFT). Spektrum frekuensi ini digunakan sebagai masukan oleh sistem pengenalan pola. neural network merupakan jenis algoritma kecerdasan yang sering dimanfaatkan untuk mengenali pola dengan banyak masukan atau menggunakan jajaran sensor.

Analisis Fourier merupakan teknik perhitungan berdasarkan komposisi sinyal terhadap sinyal asli dalam bentuk sinusoidal melalui persamaan:

$X(f)=\int_{-\infty}^{\infty} x(t) \cdot e^{-j \omega t} d t$

Karena transformasi sinyal waktu kontinyu cukup sulit untuk dilakukan, maka transformasi sinyal waktu digital harus digunakan (Discrete Fourier Transform) dengan formula:

$X(k) \sum_{n=0}^{N-1} x[n] . e^{-\frac{j 2 \pi n k}{N}}, 0 \leq k \leq N-1$

Sehingga proess penghitungan menjadi lebih sederhana dan efisien.

Sedangkan algoritma neural network, yang dikategorikan dalam sistem kecerdasan, merupakan algoritma yang menirukan kinerja sel renik yang terdapat dalam otak manusia [5]. Metode ini memerlukan tahap peniruan (pembelajaran) untuk memperbarui pembobotan setiap neuron sebelum dilakukan pengujian. Tipe neural network backpropagation menggunakan algoritma gradient descent adalah sebuah metode optimalisasi yang umum digunakan pada tahap pembelajaran karena modelnya yang simpel namum memiliki akurasi cukup tinggi. Fungsi errornya dapat dituliskan dalam persamaan:

$$
\begin{aligned}
& E_{p}=\frac{1}{2} \sum_{k}\left(t_{k}-y_{k}\right)^{2} \\
& E_{R M S}=\sqrt{\frac{\sum_{p} E_{p}}{p}}
\end{aligned}
$$

Selanjutnya pada tahap feedforward akan dihitung fungsi aktifasi untuk setiap neuron, dengan formula:

$$
\begin{aligned}
& z_{-} i n_{j}=v_{o j}+\sum_{j} x_{i} v_{i j} \\
& z_{j}=f\left(z_{-} i n_{j}\right)
\end{aligned}
$$

Sedangkan pada tahap backward propagation akan dihitung perubahan bobot dan diperbarui dengan laju pembelajaran dan momentum sebagaimana persamaan:

$$
\begin{gathered}
\Delta v_{i j}(t)=\eta \cdot \delta_{j} \cdot \frac{d f\left(z_{j}(t)\right)}{d z_{j}(t)} \cdot x_{i}(t) \\
+\mu \cdot \Delta v_{i j}(t-1) \\
\Delta v_{i j}(t)=\Delta v_{i j}(t-1)+\Delta v_{i j}(t)
\end{gathered}
$$

\section{METODE PENELITIAN}

\subsection{Perancangan Hardware \& Software}

Dalam penelitian ini, sistem deteksi kedatangan kereta api dibangun menggunakan mikrokontroller Arduino uno dan modul sensor MPU 6050 pada komunikasi digital dalam lajur bus serial [6] dengan pin data SDA dan clock SCL. Sedangkan data getaran yang dimanfaatkan dari sensor ini hanyalah data getaran pada sumbu vertikal X saja.

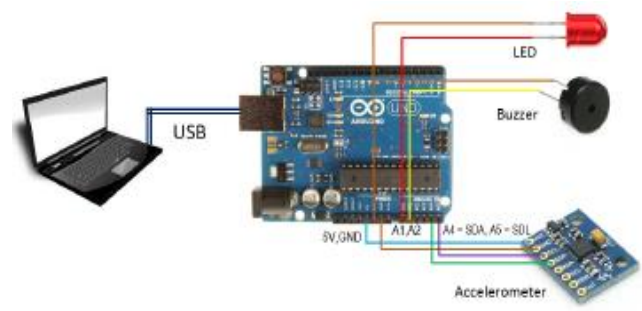

Gambar 1. Desain Hardware 
Pada koneksi USB, kecepatan transfer data dari Arduino Uno ke komputer diatur pada 115.200 bps. Kecepatan ini adalah batas maksimum modul accelerometer untuk menampung 1000 data per detik. Untuk tanda peringatan, pin digital keluaran Arduino Uno akan mengendalikan bel buzzer dan lampu LED.

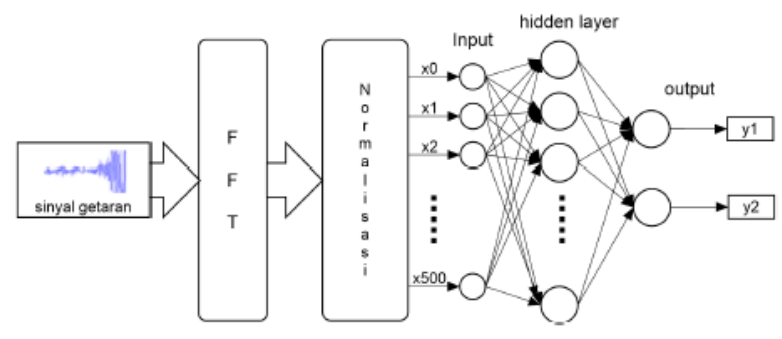

Gambar 2. Diagram Software

Software pemantauan terdiri atas blok pemrosesan FFT, normalisasi, dan neural network untuk melakukan identifikasi jenis getaran [7] . Sedangkan matriks target dipisahkan menjadi dua jenis keluaran yakni kereta dan non-kereta.

Table 1. Matriks target neural network

\begin{tabular}{|c|c|c|c|}
\hline No. & Kondisi & Kelompok & Matriks \\
\hline 1 & No Signal & \multirow{4}{*}{$\begin{array}{l}\text { Non- } \\
\text { Kereta }\end{array}$} & \multirow{4}{*}{10} \\
\hline 2 & Motor & & \\
\hline 3 & Mobil & & \\
\hline 4 & Truk & & \\
\hline 5 & Kereta & Kereta & 01 \\
\hline
\end{tabular}

\subsection{Pengambilan Data Sinyal Getaran}

Untuk mengambil sinyal getaran di lokasi penelitian, sensor ditempatkan pada posisi sesuai pada perancangan dalam Gambar 3 dimana modul sensor diikatkan di atas lempengan braket besi yang dikaitkan pada rel. Modul sensor ini dipasangkan pada posisi axis-x searah dengan arah gravitasi.

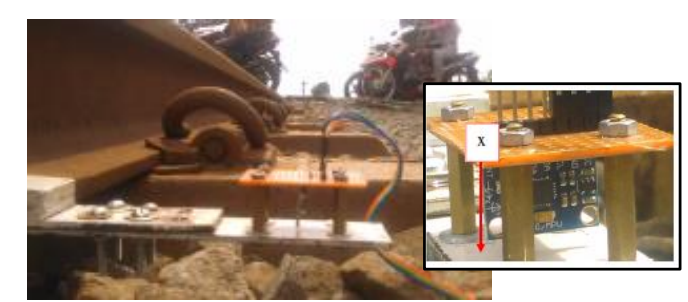

Gambar 3. Posisi Sensor Accelerometer

\section{HASIL DAN PEMBAHASAN}

Dari pengujian yang dilakukan, didapatkan data pengenalan pola kereta api dibanding kendaraan lain dan data pengukuran jarak kedatangan kereta dari titik lokasi pemantauan.

\subsection{Pengenalan Pola Getaran Kereta Api}

Keempat jenis sinyal getaran yakni kereta, truk, mobil, sepeda motor, dan no signal masing-masing 1000 data seperti dalam Gambar 4a.

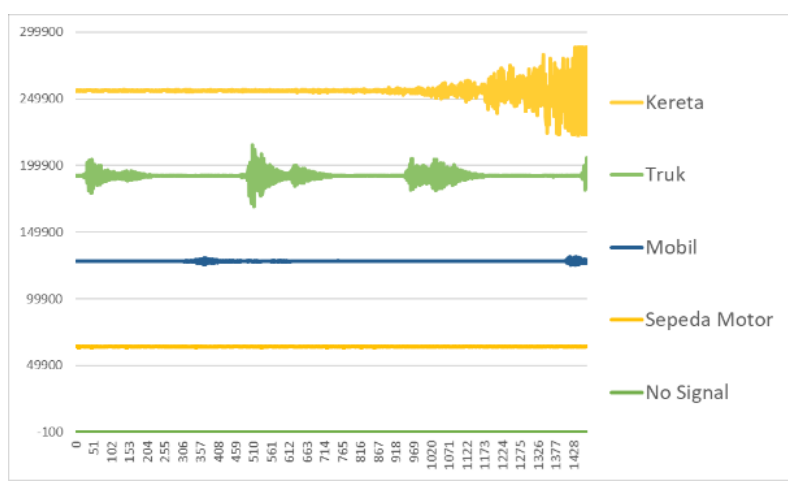

(a)

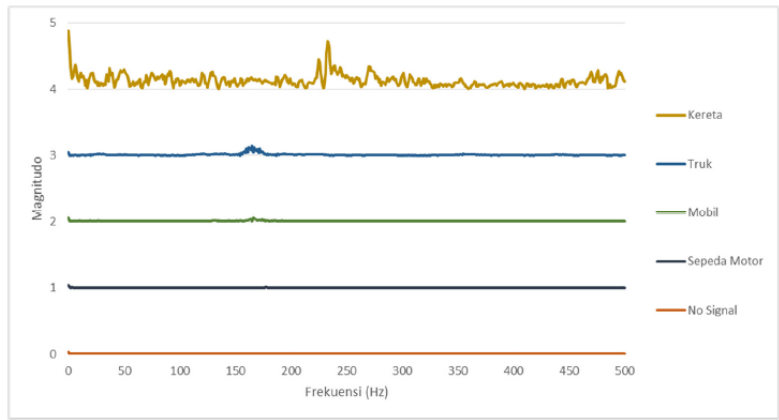

(b)

Gambar 4. Sinyal Getaran

(a) domain waktu (b) domain frekuensi

Sedangkan pola frekuensi yang ditransformasikan melalui FFT sepanjang 500 titik frekuensi seperti dalam Gambar 4b. 
Tabel 2. Jumlah data pembelajaran \& pengujian

\begin{tabular}{lcc}
\hline \multicolumn{1}{c}{ Kondisi } & $\begin{array}{c}\text { Data } \\
\text { Pembelajaran }\end{array}$ & $\begin{array}{c}\text { Pengujian } \\
\text { Data }\end{array}$ \\
\hline Non Train & 16 & 4 \\
Train & 4 & 4 \\
\hline Jumlah Data & 20 & 8 \\
\hline
\end{tabular}

Pengaturan neural network terdiri atas 501 titik pada layer masukan, 50 neuron pada hidden layer, dan 2 neuron pada layer keluaran. Fungsi aktifasi untuk setiap neuron adalah binary sigmoid. Sementara momentum konstantanya sebesar 0,6, laju pembelajaran sebesar 0,6 , dan target error sebesar 0,0001. Jumlah data pembelajaran dan data pengujian untuk sinyal kereta dan non-kereta ditunjukkan dalam Tabel 2.

Tabel 3. Nilai error pengujian

\begin{tabular}{|c|c|c|c|c|}
\hline \multirow{2}{*}{$\begin{array}{c}\text { Kondi } \\
\quad \text { si }\end{array}$} & \multirow{2}{*}{$\begin{array}{l}\text { Peng } \\
\text { ujian }\end{array}$} & \multicolumn{3}{|c|}{$M S E$} \\
\hline & & 0.01 & 0.001 & 0.0001 \\
\hline \multirow[t]{4}{*}{$\begin{array}{l}\text { Non- } \\
\text { kereta }\end{array}$} & 1 & $\begin{array}{l}\text { Non- } \\
\text { kereta }\end{array}$ & $\begin{array}{l}\text { Non- } \\
\text { kereta }\end{array}$ & $\begin{array}{l}\text { Non- } \\
\text { kereta }\end{array}$ \\
\hline & 2 & $\begin{array}{l}\text { Non- } \\
\text { kereta }\end{array}$ & $\begin{array}{l}\text { Non- } \\
\text { kereta }\end{array}$ & $\begin{array}{l}\text { Non- } \\
\text { kereta }\end{array}$ \\
\hline & 3 & $\begin{array}{l}\text { Non- } \\
\text { kereta }\end{array}$ & $\begin{array}{l}\text { Non- } \\
\text { kereta }\end{array}$ & $\begin{array}{l}\text { Non- } \\
\text { kereta }\end{array}$ \\
\hline & 4 & $\begin{array}{c}\text { Non- } \\
\text { kereta }\end{array}$ & $\begin{array}{l}\text { Non- } \\
\text { kereta }\end{array}$ & $\begin{array}{l}\text { Non- } \\
\text { kereta }\end{array}$ \\
\hline \multirow[t]{4}{*}{ Kereta } & 1 & Kereta & Kereta & Kereta \\
\hline & 2 & Kereta & Kereta & Kereta \\
\hline & 3 & Kereta & Kereta & Kereta \\
\hline & 4 & Kereta & Kereta & Kereta \\
\hline Pers & tase & $100 \%$ & $100 \%$ & $100 \%$ \\
\hline
\end{tabular}

Hasil identifikasi pola getaran oleh neural network pada tahap pengujian ditunjukkan dalam tabel. Dari hasil pengujian tersebut terlihat bahwa perangkat lunak neural network dapat membedakan pola frekuensi antara kereta api dan non-kereta api dengan tingkat keberhasilkan sebssar $100 \%$.

\subsection{Deteksi Jarak Kereta Api}

Pada pengambilan data selama 13.5 detik, sinyal getaran kereta api muncul dan naik dengan amplitudo 520 bit yang tentunya pada detik selanjutnya semakin naik.

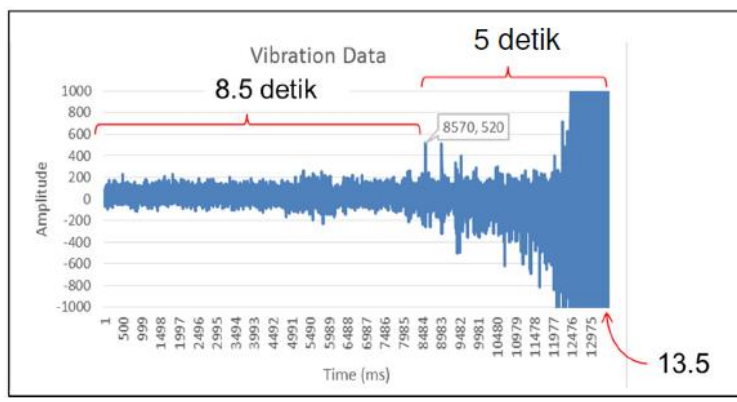

Gambar 6. Deteksi Jarak Getaran Kereta

Sehingga dalam pengukuran jarak, sinyal getaran kereta api pada domain waktu dalam Gambar 6 tersebut menjadi referensi kedatangan kereta api pada jarak 74 meter dari titik lokasi sensor accelerometer. Atau dengan kata lain, posisi kereta api dapat terdeteksi 5 detik sebelum sampai pada titik lokasi pemantauan pada kecepatan 14.8 $\mathrm{m} /$ detik atau $53.26 \mathrm{~km} / \mathrm{jam}$.

Tabel 4. Hasil Pengukuran Jarak Kereta

\begin{tabular}{cccc}
$\begin{array}{c}\text { Waktu } \\
\text { datang } \\
(\text { det })\end{array}$ & $\begin{array}{c}\text { Kecepatan } \\
(\mathrm{m} / \text { detik })\end{array}$ & $\begin{array}{c}\text { Waktu } \\
\text { deteksi } \\
(\text { det })\end{array}$ & $\begin{array}{c}\text { Jarak } \\
\text { deteksi } \\
(\mathrm{m})\end{array}$ \\
\hline 13.5 & 14.8 & 8.5 & 74
\end{tabular}

\section{KESIMPULAN}

Dalam penelitian ini telah dibangun satu sistem deteksi kedatangan kereta api. Pada keseluruhan 20 data pembelajaran dan 8 data pengujian, pola frekuensi getaran kereta api dapat dikenali menggunakan neural network dengan tingkat keberhasilan $100 \%$ dari pola getaran kendaraan lain, baik dengan error rate $0.01,0.001$, maupun pada 0.0001. Dan sensor digital accelerometer mampu membaca posisi getaran kereta api hingga jarak terjauh 74 meter dengan kecepatan kereta api sebesar 53.24 km/jam.

\section{DAFTAR PUSTAKA}

[1] "Catat, Angka Kecelakaan di

Perlintasan Kereta Api Masih Tinggi - Portal Industri Otomotif Indonesia News, Manufaktur, \& Gaya Hidup 
Terkini."

https://www.motoris.id/industri/indust ri-logistik/41345/catat-angkakecelakaan-di-perlintasan-kereta-apimasih-tinggi/ (accessed Nov. 15, 2020).

[2] Dadang, "Cegah Kecelakaan Kereta Api dengan Sensor Getar - ITS News," ITS News, 2015. .

[3] A. Goslie, F. T. Fadilah, S. Supriyadi, and A. Nalhadi, "Sistem Alarm untuk Mendeteksi Kedatangan Kereta Api," Wikrama Parahita J. Pengabdi. Masy., vol. 2, no. 1, p. 28, May 2018, doi: 10.30656/jpmwp.v2i1.612.

[4] "Fundamentals of signals and systems (eBook, 2006) [WorldCat.org]."

https://www.worldcat.org/title/funda mentals-of-signals-andsystems/oclc/568308505 (accessed Nov. 15, 2020).

[5] "Artificial neural network Wikipedia."

https://en.wikipedia.org/wiki/Artificia 1_neural_network (accessed Nov. 15, 2020).

[6] V. Ziemann, A Hands-On Course in Sensors Using the Arduino and Raspberry Pi. CRC Press, 2018.

[7] P. T. Asri, M. Rivai, and T. Tasripan, "Sistem Pendeteksi Kepatahan Mata Bor pada Mesin Cetak PCB Berdasarkan Analisa Getaran Spindle Menggunakan Teensy Board," J. Tek. ITS, vol. 7, no. 1, pp. A98-A103, Mar. 2018, doi: 10.12962/j23373539.v7i1.28496. 